\section{Estudo (Debate}

em Testão Plamejamento
Revista Estudo \& Debate, Lajeado, v. 23, n. 2, 2016. ISSN 1983-036X

DOI: http://dx.doi.org/10.22410/issn.1983-036X.v23i2a2016.1139

\title{
ÁGUA - DIREITO HUMANO FUNDAMENTAL ${ }^{1}$
}

\author{
Josiane Paula da Luz ${ }^{2}$, Luciana Turatti ${ }^{3}$, Jane Marcia Mazzarino ${ }^{4}$
}

\begin{abstract}
Resumo: A imprescindibilidade da água para a manutençâo da vida tem mobilizado a sociedade civil no sentido de se atribuir a tal bem a condição de direito humano. Neste sentido, o presente artigo apresenta a evolução normativa nacional e internacional que contribui para o reconhecimento da água como direito humano. O estudo decorre de uma pesquisa bibliográfica e documental que se debruça sobre as principais legislaçóes e documentos elaborados pela sociedade civil referentes ao tema, envolvendo seu reconhecimento como direito humano e fundamental, destacando deliberações e Conferências da Organização das Nações Unidas (ONU); Constituiçẫo Federal de 1988 e Lei no 9433/1997, que institui a Política Nacional de Recursos Hídricos e cria o Sistema Nacional de Gerenciamento de Recursos Hídricos, além de pesquisa bibliográfica em doutrina especializada. A análise realizada demonstrou que até o presente momento inexiste um documento formal que tenha sido ratificado por todos os países que reconheça a água como direito humano. A inexistência deste documento, no entanto, não é óbice para o reconhecimento tácito desta condição, o qual é extraído dos demais documentos investigados. Este reconhecimento, contudo, se revela insuficiente, devendo haver maior comprometimento para concretização do direito à água por meio de práticas perenes dos Estados e da participação da sociedade.
\end{abstract}

Palavras-chave: Água. Direito Humano. Direito Fundamental. Método qualitativo.

1 Esta pesquisa tem apoio da CAPES (Coordenação de Aperfeiçoamento de Pessoal de Nível Superior) e FAPERGS (Fundação de Amparo à Pesquisa do Estado do Rio Grande do Sul).

2 Mestre em Ambiente e Desenvolvimento (2012) e graduação em Direito (2006) pelo Centro Universitário Univates. Professora adjunta do Instituto Federal Sul-Rio-grandense (IFSUL), Câmpus Venâncio Aires, licenciada para realizaçấo do Doutorado. E-mail: josianeluz@ifsul.edu.br.

3 Doutora em Direito pela Universidade de Santa Cruz do Sul - UNISC (2014), mestrado em Direito pela UNISC (2003) e graduaçáo em Ciências Jurídicas e Sociais pela UNISINOS (2001). Professora adjunta do Centro Universitário Univates, Coordenadora Adjunta do Curso de Direito, professora de cursos de especialização na área ambiental e constitucional na UNIVATES e UNISINOS e professora colaboradora do PPG em Ambiente e Desenvolvimento da UNIVATES. E-mail: lucianat@univates.br.

4 Doutora em Ciências da Comunicaçáo pela Universidade do Vale do Rio dos Sinos - UNISINOS (2005), com estágio doutoramento na Universidade Nova de Lisboa (UNL), mestrado em Ciências da Comunicação pela UNISINOS (2001) e graduação em Comunicação Social com Habilitação em Jornalismo pela UNISINOS (1991). Professora adjunta do Centro Universitário Univates. Atua no PPG em Ambiente e Desenvolvimento (mestrado e doutorado), e na graduação em Comunicação Social. E-mail: janemazzarino@univates.br. 


\title{
WATER - A FUNDAMENTAL HUMAN RIGHT
}

\begin{abstract}
The indispensability of water to the maintenance of life has mobilized the civil society in the sense of laying to that good the condition of human right. Therein, this article presents the development of the national and international regulations that contributes to the recognition of water as a human right. The study derives from a bibliographic and documentary research that focuses on the main legislation and documents prepared by the civil society on this topic, involving its recognition as human and fundamental right, highlighting deliberations and Conferences of the United Nations (UN); Federal Constitution of 1988, and Law No. 9433/1997, which establishes the National Water Resources Policy and creates the National System of Water Resources Management, as well as the literature by specialized doctrine. The carried out analysis showed up to this moment that there is no formal document that has been ratified by all countries recognizing water as a human right. The inexistence of such document, nevertheless, is not an obstacle to the tacit recognition of this condition, which is extracted from other investigated documents. This recognition, however, is clearly insufficient, there must be a greater commitment for the achievement of the right to water through perennial practices of the States and participation of society.
\end{abstract}

Keywords: Water. Human Right. Fundamental Right. Qualitative Method.

\section{INTRODUÇÃO}

Debates sobre os recursos hídricos têm recebido cada vez mais destaque tanto nas pesquisas científicas como no cotidiano social, o que acaba influenciando diretamente no regramento jurídico. Questôes como o desmatamento desenfreado, a fragmentação florestal, a utilização de espécies exóticas, a poluição por agrotóxicos, a extinção de populações e espécies da fauna e flora e a crise hídrica vivenciada em várias regiōes, vêm tornando estes assuntos cada vez mais discutidos, especialmente no que se refere à disponibilidade e qualidade da água e diminuição de espaços preservados.

No presente estudo realiza-se uma breve contextualização global acerca das principais regulações referentes aos recursos hídricos para após observar como o tema foi tratado no cenário brasileiro, por meio de uma análise interpretativa da Constituição Federal (CF/1988). Na sequência apresenta-se o tratamento dispensado à água pela doutrina que a eleva ao status de direito fundamental. Para construção desta ideia foram analisados 03 documentos da Organização das Naçóes Unidas (ONU) em específico: o Comentário Geral no 15 de 2002, do Comitê de Direitos Econômicos, Sociais e Culturais, a Resolução 64/292, de 28 de julho de 2010 e a Resolução 15/09 de 30 de setembro de 2010.

O objetivo é investigar em que medida estes documentos e autores da área atribuem à água a condição de direito humano e fundamental. Com base em tais análises apresentam-se ainda as implicaçóes e consequências deste entendimento, principalmente pelo fato da construção teórica dos direitos humanos ser fortemente influenciada pela visão antropocêntrica.

\section{Breve contexto global acerca da água}

A preocupação com a regulação e preservação das águas não é um tema contemporâneo. Registros apontam que experiências em gestão de bacias hidrográficas já tinham sido vivenciadas em 1616 no Rio Danúbio, e em 1922 no pacto do rio Colorado, que decidia sobre a partição da utilização da água desse rio entre os Estados que compartilhavam a 
mesma bacia hidrográfica. Também em 1933 na bacia do Rio Tennessee debatia-se sobre o compartilhamento da água que envolvia o território de sete estados dos Estados Unidos da América (EUA), lembra Berreta (2013). Mas a prática mais influente, segundo o autor, que relacionou a gestão das águas com bacias hidrográficas e participação social, ocorreu na bacia do rio Ruhr, na Alemanha. Em 1913, ela já estabelecia que todos os associados (empresas, municípios e comunidades) seguiriam a política acordada na "Assembleia de Associados" ou "Parlamento da Água". Definia também a cobrança pelo uso, cujos recursos eram utilizados para investimentos necessários à bacia e outras atividades relacionadas à gestão da Associação. Este modelo de gestão de águas se espalhou pela região e países vizinhos, sendo tal lógica incorporada pela primeira Lei das Águas francesa, a mesma que, vinte anos depois, influenciou a Lei das Águas do Rio Grande do Sul - Brasil (Lei no 10.350/1994).

Mais recentemente fixa-se um importante marco na discussão global sobre a proteção das águas por meio da Declaração de Estocolmo - Conferência das Nações Unidas sobre Meio Ambiente Humano, de 1972. Nesta Declaração encontram-se 26 princípios fundamentais que, segundo Silva (2011) constituem-se como um prolongamento da Declaração Universal dos Direitos do Homem e influenciaram na elaboração do capítulo que trata sobre o meio ambiente na Constituição Federal Brasileira de 1988. Os princípios consagrados na Conferência de Estocolmo são designados por Silva (2011) como princípios internacionais de proteção ambiental.

Medeiros (2004, pág. 44) afirma que, a partir dessa Convenção, as nações "passaram a compreender que nenhum esforço, isoladamente, seria capaz de solucionar os problemas ambientais do Planeta”. Para Carvalho (2001, p. 18) a Conferência foi fundamental por introduzir no universo jurídico internacional o conceito de direito ambiental. "Os princípios 21 e 22, notadamente, da Declaração de Estocolmo, estabeleceram a responsabilidade de cada país pelos danos que as atividades, dentro de sua jurisdição, possam causar ao ambiente de outros países". Carvalho considera um avanço significativo no campo jurídico e social o fato de se estabelecer de modo efetivo a corresponsabilidade pela manutenção da qualidade ambiental.

Em 1992, na Conferência de Dublin - Conferência Internacional de Água e Meio Ambiente - apontou-se a existência de sérios problemas relacionados à disponibilidade hídrica. No evento se estabeleceram princípios para a gestão sustentável da água. O relatório da Conferência sugeriu açóes locais, nacionais e internacionais, propondo uma gestão dos recursos hídricos de forma integrada, considerando os aspectos físicos, sociais e econômicos. Para que essa integração tivesse o foco adequado, sugeriu-se que a gestão fosse baseada em bacias hidrográficas com enfoque participativo, envolvendo usuários e governo de todos os níveis. A abordagem participativa sugerida pelo relatório da Conferência se apoia na necessária conscientização da importância da água e na tomada de decisóes locais, assegurada, para tanto, a participação ampla e consulta pública, com o engajamento dos usuários no planejamento e implementação dos projetos.

Também em 1992 ocorre no Rio de Janeiro a Conferência das Nações Unidas sobre o Meio Ambiente e Desenvolvimento, que reafirmou os princípios de Estocolmo e adicionou outros sobre o desenvolvimento sustentável e o meio ambiente. Silva (2011), comentando 
o Princípio 1 da Conferência, argumenta que o ponto de partida é o reconhecimento da natureza interdependente e integral da Terra e a compreensão de que os seres humanos estão no centro das preocupaçóes quando se trata do desenvolvimento sustentável, tendo direito a uma vida saudável e produtiva, em harmonia com a natureza.

Esta Conferência marcou o surgimento e o fortalecimento de inúmeras organizaçóes da sociedade civil e também a promulgação de leis protetivas em relação ao meio ambiente na grande maioria dos países, além de textos inflamados em favor de uma melhor qualidade de vida. Conhecida como "Cúpula da Terra", a Conferência se tornou uma importante e ambiciosa negociação multinacional jamais realizada na história para tratar de assuntos tão complexos e abrangentes, debatendo uma variada gama de assuntos, lembra Carvalho (2001).

Dentreos resultados da Conferência Rio 1992 destacam-se: a subscrição de documentos e fixação de princípios normativos a serem adotados pelos governos, como a Agenda 21 que estabelece cinco questões principais referentes à organização e gestão de recursos hídricos: a) desenvolvimento e gerenciamento integrado de recursos hídricos, incluindo questóes tecnológicas, socioeconômicas, ambientais e de saúde humana; b) provisão de água potável de qualidade adequada e saneamento básico para toda a população; c) água para a produção de alimento sustentável e desenvolvimento rural; d) proteção dos recursos hídricos, dos ecossistemas aquáticos continentais e da qualidade da água; e) promoção de tecnologias e açóes que integrem os setores público e privado no desenvolvimento e na inovação tecnológica (BRASIL, 1992). Este evento contribuiu sobremaneira para que ocorresse uma ampla alteração conceitual no processo de planejamento e gestão dos recursos hídricos, reconhecendo a água doce como recurso finito e indispensável para a sobrevivência de todas as espécies.

Em 2002, na África, foi realizada a Cúpula Mundial sobre Desenvolvimento Sustentável, na cidade de Johanesburgo. A reunião promovida pela ONU ficou também conhecida como Rio+10, e discute em dois capítulos a questão da água e como a privação deste bem interfere em uma vida digna, reconhecendo seu acesso como uma necessidade básica dos povos.

13. O meio ambiente global continua sofrendo. A perda de biodiversidade prossegue, estoques pesqueiros continuam a ser esgotados, a desertificação toma mais e mais terras férteis, os efeitos adversos da mudança do clima já são evidentes e desastres naturais têm sido mais frequentes e mais devastadores; países em desenvolvimento são mais vulneráveis e a poluiçâo do ar, da água e do mar segue privando milhôes de pessoas de uma vida digna. 18. Acolhemos o foco da Cúpula de Joanesburgo na indivisibilidade da dignidade humana e estamos resolvidos, por meio de decisões sobre metas, prazos e parcerias, a ampliar rapidamente o acesso às necessidades básicas como a água potável, o saneamento, habitação adequada, energia, assistência médica, segurança alimentar e a proteção da biodiversidade [...] (BRASIL, 2003).

E novamente no Rio de Janeiro, ocorreu em 2012, a Rio+20 - Conferência das Nações Unidas Sobre Desenvolvimento Sustentável (BRASIL, 2012). O documento final do evento, intitulado: "O futuro que queremos", traz em capítulo específico sobre água e saneamento, onde os países signatários reconhecem que a água ocupa papel central no 
desenvolvimento sustentável e assumem, entre outros, o compromisso de reduzir o número de pessoas sem acesso à água potável, além de reconhecerem a necessidade de que sejam adotadas medidas para enfrentar enchentes, secas, reduzir a poluição e melhorar a qualidade da água.

A Rio+20 destaca-se ao reafirmar o reconhecimento da água como direito humano, garantindo a manutençáo da soberania dos países, como se observa na leitura do item 121: "Reafirmamos nossos compromissos em relação ao direito humano à água potável e ao saneamento, que devem ser progressivamente realizados para nossas populaçóes com pleno respeito à soberania nacional" (BRASIL, 2012).

Cabe referir também em nível global a importância dos documentos aprovados pela ONU sobre os recursos hídricos, os quais, contudo, serão tratados em tópico específico devido à importância que assumem para o tratamento da água como direito humano.

\section{2 Água como direito fundamental no contexto brasileiro}

A ampla proteçáo ao meio ambiente assegurada pela CF/1988, aliado as garantias conquistadas por meio das normas internacionais alçam o meio ambiente à condição de direito fundamental. Segundo Sarlet e Fensterseifer (2010, p. 13), a CF/1988 "atribuiu à proteção ambiental o status de direito fundamental do indivíduo e da coletividade, além de consagrar a proteção ambiental como um dos objetivos ou tarefas fundamentais do Estado - Socioambiental - de Direito brasileiro". O autor também defende que, com esse reconhecimento, o Estado estará obrigado a respeitar os direitos fundamentais, em função da garantia (princípio) constitucional da proibição do retrocesso. Desta forma, sendo o meio ambiente elevado a direito fundamental, reforça-se a ideia de que a água, por estar inclusa no meio ambiente, também possui este caráter.

A CF/1988, além de firmar importantes direitos e garantias fundamentais, apresenta um capítulo específico sobre o Meio Ambiente. O texto constitucional estabelece a dignidade da pessoa humana como um de seus fundamentos e o bem social como um dos objetivos fundamentais, (Art. 1 ${ }^{\circ}$, III e art. $3^{\circ}$, IV da CF/1988), compreendendo-se daí que, sendo a água um bem essencial para o desenvolvimento das atividades do ser humano, é necessário que o Estado tenha capacidade de garantir o acesso em qualidade e quantidade para os cidadáos.

Em relação ao meio ambiente, a CF/1988, cria um capítulo específico como já referido. Em seu art. 225, dispõe que: "Todos têm direito ao meio ambiente ecologicamente equilibrado, bem de uso comum do povo e essencial à sadia qualidade de vida, impondose ao Poder Público e à coletividade o dever de defendê-lo e preservá-lo para as presentes e futuras geraçôes". Inúmeras outras legislações esparsas brasileiras têm também como principal objetivo proteger o meio ambiente dentro dos objetivos propostos pela CF/1988. Juristas apontam o capítulo referente ao meio ambiente como sendo um dos mais avançados e modernos do constitucionalismo mundial, contendo regras de notável amplitude e de reconhecida utilidade, conforme mencionam Mendes, Coelho e Branco (2010).

No art. 21, XIX da Carta Magna também se encontra o fundamento legal da criação da Lei no. 9433/1997, que institui a Política Nacional de Recursos Hídricos e cria o Sistema 
Nacional de Gerenciamento de Recursos Hídricos (SNGRH): “Art. 21. Compete à União: [...] XIX - instituir sistema nacional de gerenciamento de recursos hídricos e definir critérios de outorga de direitos de seu uso" (BRASIL, 1988), já nos art. 20 e 26 da CF/1988 ficam estabelecidas regras de dominialidade ${ }^{5}$.

Embora haja a categorização expressa da água como um bem público, doutrinariamente se defende ser a água um bem difuso. Fiorillo (2003, p. 405) defende esta linha sustentando que a água é "bem de natureza jurídica difusa". Caubet (2008, p. 143), da mesma forma, afirma este caráter difuso, acrescentando que "a lei incorre em erro ao estabelecer que a água é um bem de domínio público”. Este pensamento é endossado por Mancuso (2005, p. 62): "Sendo assim, a água um bem comum de todos (res communes omnium), ajusta-se ao conceito de interesse difuso". Esta teoria, para Viegas (2012) dá suporte à possibilidade de se concluir que a água corrente ou depositada em território brasileiro não é de ninguém e, ao mesmo tempo, é de todos, tratando-se de um bem da humanidade, pois não é propriedade particular, nem pública.

$\mathrm{Na}$ norma matriz que trata do meio ambiente em nível constitucional, tem-se a previsão de responsabilidade ambiental entre geraçóes. Para Machado (2011) o art. 225 aclama a ética da solidariedade entre as geraçôes, de modo que as geraçóes presentes não podem fazer uso do meio ambiente gerando escassez e debilidade para as futuras. "O princípio cria um novo tipo de responsabilidade jurídica: a responsabilidade ambiental entre geraçôes" (MACHADO, 2011, p. 140), ou intergeracional. Esta responsabilidade ambiental entre geraçóes aumenta a responsabilidade que os gestores, especialmente de recursos hídricos possuem, eis que é sabido que a água é um recurso finito, que precisa ser preservado - e gerenciado para tal - para que se garanta que as futuras geraçóes tenham acesso a esse bem vital. Também aumenta a responsabilidade de todos os cidadãos, eis que esta é compartilhada, chamando todos a participarem de processos de gestão e se envolverem como tema.

Percebe-se que a CF/1988 representa um marco importante na proteção das águas e do meio ambiente. Além do art. 225, tem-se nos arts. $1^{\circ}$, III e art. 3º IV, o estabelecimento da dignidade da pessoa humana como um de seus fundamentos e o bem social como um dos objetivos fundamentais, pois não há como ter uma vida digna e viver em um estado de bem-estar social se o indivíduo não possuir, para tal, um meio ambiente minimamente preservado e acesso à água potável.

5 Art. 20. São bens da Uniấo:

III - os lagos, rios e quaisquer correntes de água em terrenos de seu domínio, ou que banhem mais de um Estado, sirvam de limites com outros países, ou se estendam a território estrangeiro ou dele provenham, bem como os terrenos marginais e as praias fluviais;

Art. 26. Incluem-se entre os bens dos Estados:

I - as águas superficiais ou subterrâneas, fluentes, emergentes e em depósito, ressalvadas, neste caso, na forma da lei, as decorrentes de obras da União;

II - as áreas, nas ilhas oceânicas e costeiras, que estiverem no seu domínio, excluídas aquelas sob domínio da União, Municípios ou terceiros (BRASIL, 1988). 
Na legislação infraconstitucional, o Brasil destaca-se com a Lei no 9433/1997, que institui a Política Nacional de Recursos Hídricos e cria o Sistema Nacional de Gerenciamento de Recursos Hídricos, representando um marco legal em termos de recursos hídricos no país. Logo no seu artigo $1^{\circ}$ apresenta seus fundamentos ${ }^{6}$, percebendo-se que esta propõe um novo olhar sobre a água. No inciso I ela denomina ser a água um bem de domínio público, isto implica dizer que ninguém pode se apoderar da água, ou seja, não existe a propriedade da água. Assim, ficou cristalizada por meio de legislação infraconstitucional, o que a Lei Magna já havia instituído que é o caráter público integral da propriedade da água. Lembra Viegas (2012) que, foi após a ediçâo da Lei no 9433/1997, que a comunidade jurídica passou a sustentar com mais vigor a tese da extinção integral da propriedade privada dos recursos hídricos.

Vários estudos consideram o acesso à água potável e ao saneamento como um direito fundamental incluso na cláusula pétrea da dignidade humana (art. $1^{\circ}$, III da Constituição Federal) (MIRANDOLA; SAMPAIO, 2006; WOLKMER; MELO, 2013; VILLAR, 2013). Também há a defesa de que o direito ao meio ambiente sadio está intimamente ligado ao direito fundamental à vida, pois para que haja condiçóes de vida no planeta, é necessário assegurar um piso vital mínimo de direitos, que, segundo Fiorillo (2013) estão fixados no art. $6^{\circ}$ da $\mathrm{CF} / 1988$ e se constituem em um conjunto de direitos que devem ser assegurados pelo Estado a todas as pessoas, dentre os quais se sobressai o direito à saúde, para cujo exercício é imprescindível um meio ambiente equilibrado e sadio, e isto inclui, com obviedade, o acesso com qualidade aos recursos hídricos.

A CF/1988, neste sentido, coaduna-se com o quinto item da Declaração dos Direitos da Água (ONU, 1992), no qual se afirma que: "A água não é somente uma herança dos nossos predecessores; ela é, sobretudo, um empréstimo aos nossos sucessores. Sua proteção constitui uma necessidade vital, assim como a obrigaçáo moral do homem para com as geraçôes presentes e futuras". Também no 4º Fórum Mundial da Água, realizado em 2006 na Cidade do México uma importante reflexão é realizada no documento denominado " $O$ direito à água - do conceito à implementação". Ele refere que a falta de acesso à água acaba por interferir diretamente na fruição dos demais direitos humanos, como, por exemplo, o direito à educação, nível de vida adequado, saúde, alimentação, o que torna esse direito imprescindível para que o ser humano viva com dignidade (CONSELHO MUNDIAL DA ÁGUA, texto digital, 2006).

Embora o direito à água não esteja reconhecido expressamente no texto constitucional, uma análise interpretativa da $\mathrm{CF} / 1988$, especialmente dos art. $1^{\circ}$, III e art. $3^{\circ}$, IV, que estabelecem a dignidade da pessoa humana como um de seus fundamentos e o bem social

6 Art. $1^{\circ}$, I - a água é um bem de domínio público; II - a água é um recurso natural limitado, dotado de valor econômico; III - em situaçóes de escassez, o uso prioritário dos recursos hídricos é o consumo humano e a dessedentaçáo de animais; IV - a gestão dos recursos hídricos deve sempre proporcionar o uso múltiplo das águas; V - a bacia hidrográfica é a unidade territorial para implementação da Política Nacional de Recursos Hídricos e atuação do Sistema Nacional de Gerenciamento de Recursos Hídricos; VI - a gestão dos recursos hídricos deve ser descentralizada e contar com a participação do Poder Público, dos usuários e das comunidades (BRASIL, 1997). 
como um dos objetivos fundamentais, e do teor do art. 225, conduz a compreensão de que a água é de fato direito fundamental.

\section{3 Água como direito humano}

Os direitos humanos e o meio ambiente estão interligados, pois sem os direitos humanos, a proteção ambiental não alcança eficácia, e sem a inclusão do meio ambiente neste rol, os direitos humanos correriam o perigo de perder sua função central, que é a proteção à vida humana, seu bem-estar e sua integridade, como defende Bosselmann (2010). O autor lembra que existe um reconhecimento jurídico crescente da ideia de que a degradação ambiental pode resultar em privaçóes de direitos humanos já existentes, e lembra que em escala global 56 constituiçóes reconheceram explicitamente o direito a um meio ambiente limpo e saudável, o que sugere que o direito ao meio ambiente é um direito humano in statu nascendi.

Analisando-se a perspectiva de Bobbio (1992) acerca das geraçóes de direito ${ }^{7}$, ou também chamadas dimensôes - incluindo o Direito ao Meio Ambiente equilibrado - tem-se que existe uma multiplicação de direitos que torna a discussão sobre sua efetivação complexa, reconhecendo que a formulação de normas sobre meio ambiente e recursos hídricos editadas nas últimas décadas, em vários países, inclusive no Brasil, resultaram de uma resposta às necessidades experimentadas pela sociedade, que decidiu que era o momento de ocorrerem mudanças nas relações 'homem-natureza'.

Ao se realizar uma análise sobre o posicionamento da Organização das Naçôes Unidas (ONU) sobre a questão, observam-se alguns marcos importantes. Em novembro de 2002 foi aprovado o Comentário Geral no 15 do Comitê de Direitos Econômicos, Sociais e Culturais, que inclui em seu texto que o direito à água é pressuposto para o exercício e o cumprimento dos demais direitos humanos, pois se revela como essencial para uma vida digna (TURATTI, 2014). O referido Comentário Geral contempla em seu conteúdo que a água deve ser tratada como um bem social e cultural, e não como um bem econômico, e que o exercício desse direito deve ocorrer de modo sustentável, para que se garanta o direito das futuras geraçóes de acesso a esse bem. Alguns fatores apontados pelo Comentário devem ser considerados em qualquer situação, sendo eles: disponibilidade, qualidade, acessibilidade (física, econômica, não discriminação e acesso à informação).

No referido documento, o direito à água impóe aos Estados três níveis de obrigaçóes: a) respeitar ou abster-se de obstaculizar o exercício do direito à água, evitando atividades que limitem o acesso à água em condiçóes de igualdade, abster-se de intervir arbitrariamente nos sistemas tradicionais de distribuição e abster-se de contaminar a água; b) proteger ou impedir que terceiros obstacularizem o desfrute do direito à água; c) cumprir a obrigação de facilitar, promover e garantir o acesso à água potável (ONU, 2002).

7 Para Bobbio (1992): Primeira geração: Direitos individuais e políticos; Segunda geração: Direitos sociais; Terceira geração: Direitos transindividuais, coletivos (meio ambiente, consumidor) e difusos; Quarta geração: Direitos de manipulação genética; Quinta geração: Direitos ligados à realidade virtual. 
O dia 28 de julho de 2010 revela-se como um marco mundial no contexto das lutas históricas pela efetivação do acesso à água, tendo em vista o reconhecimento pela ONU por meio da Resolução no 64/292, do acesso à água potável e ao saneamento básico como um Direito Humano. Por meio de proposta da Bolívia, por 122 votos a favor, nenhum contra e 41 abstençóes, conclamaram-se os Estados e os organismos internacionais a prover recursos financeiros e transferência de tecnologias, particularmente para os países em desenvolvimento, com vistas a aumentar os esforços de garantir a efetivaçáo do acesso humano à água. A Resolução coloca a problemática hídrica entre o rol dos valores essenciais do ser humano, em uma concepçáo de universalidade, indivisibilidade, interdependência e inter-relação atribuída aos aludidos direitos. Dentre as diversas consequências trazidas por essa declaraçáo, destaca-se a obrigaçáo política dos Estados Nacionais perante a comunidade internacional, no sentido de garantir a efetividade do acesso à água, desdobrando-se em três deveres fundamentais: respeitar, proteger e cumprir, conforme ressalta Ramos (2015).

Dois meses depois, em 30 de setembro de 2010, o Conselho de Direitos Humanos das Nações Unidas aprovou a Resolução no ${ }^{\circ}$. 15/09, que afirma que a água e o saneamento são direitos humanos "indissoluvelmente associados ao mais alto nível de saúde física e mental possível, assim como, ao direito à vida e à dignidade humana", explica Turatti (2014). Segundo a autora, a compreensão de que a água é direito humano já podia ser extraída, de forma indireta, da Declaraçấo Universal dos Direitos Humanos da ONU de 1948, quando se garantiu o direito à vida, já que não há como ter vida sem água. "A falta de referência direta a este direito talvez se deva ao fato de que na época náo se poderia imaginar que a água viria a se tornar escassa e que fosse necessário expressar sua importância em um documento internacional como forma de garantir seu acesso" (TURATTI, 2014, p. 38).

Observa-se que em termos globais vem se fortalecendo a compreensão da água como direito humano, devido a sua imprescindibilidade à vida (TURATTI, 2014; LEFF, 2010; SHIVA, 2008). D'Isep (2010) também defende a água como direito humano afirmando que: "o direito à água reflete-se em todo o sistema jurídico, ao se manifestar como princípio universal de direito humano fundamental à água-vida” (D'ISEP, 2010. p. 58).

Para Bravo (2014) a água é um direito humano, bem público, econômico e vulnerável, já que o ser humano precisa de água assim como precisa de oxigênio. Ela afeta todos os aspectos do desenvolvimento, pois quem não tem acesso à água potável, terá suas escolhas e liberdades limitadas pela pobreza, doenças e vulnerabilidade. Quando se menciona o desenvolvimento humano, inclusa está a dignidade humana, que não se limita às necessidades físicas, pois envolve também necessidades na esfera moral. No que diz respeito à água, "[...] no se trata sólo de "dar" agua para tapar bocas o calmar conciencias, sino que debe reflejar esa preocupación por la dignidad individual y la justicia social” (BRAVO, 2014, p. 07).

É preciso compreender que o direito humano à água é o fundamento para o cumprimento de outros direitos essenciais que devem ser compreendidos como obrigaçóes que refletem valores fundamentais universais, não podendo ser considerados meros direitos opcionais que podem ficar a mercê de caprichos políticos, pois, sem acesso à água, ficam intangíveis outros, especialmente a saúde (BRAVO, 2014). Parte da comunidade internacional ainda precisa reconhecer tacitamente que o acesso à água potável e ao saneamento deve compor o âmbito dos direitos humanos. Embora ainda não reconhecido 
expressamente como tal, as normas internacionais de direitos humanos incluem obrigaçóes específicas sobre o acesso à água potável, para os Estados, no sentido de garantir a todos o acesso à água potável suficiente para o uso pessoal e doméstico, o que permite, por consequência, sustentar o status desse direito com "direito humano", afirma o autor.

$\mathrm{O}$ reconhecimento do direito à água no texto constitucional e na legislação de diversos países ${ }^{8}$ representa um avanço significativo na implementação desse direito, porém, solicita políticas públicas eficientes, com reservas específicas para estes fins nos orçamentos públicos, sob pena de ser mais um direito inoperante, com impacto textual, mas vazio de conteúdo, lembra Bravo (2014). Se deve também garantir que o acesso à água seja universal, pois, segundo o autor, vive-se a privatização deste bem, num processo que vem mascarado pela crise, com custos altos de distribuição e saneamento, que muitos não podem arcar. No Brasil, há algumas notícias de intenção de privatização das águas do Aquífero Guarani, reserva de água doce com mais de 1,2 milhão de $\mathrm{Km}^{2}$, sendo $840.000 \mathrm{Km}^{2}$ em território brasileiro, que merece atenção da sociedade, tendo em vista a prevalência do viés econômico que pode haver em uma privatização desta natureza, que privilegia poucos em detrimento de muitos ${ }^{9}$.

Portanto, é necessário estabelecer condições de igualdade para todos os cidadãos, não só garantindo o abastecimento, mas também que a água seja de qualidade, limpa, própria para o consumo, pois isso também desencadeará um processo de desenvolvimento social e econômico. "O não reconhecimento da água como direito humano pode tornar ainda mais desigual, e até mesmo letal, a vida daqueles que já são considerados desiguais por questóes sociais e de renda" (TURATTI, 2014, p. 47).

Sua concretização impóe uma nova cultura para a água, que seja capaz de reconhecer o caráter intergeracional que lhe foi reservado, como bem que pertence à presente e às futuras geraçóes. Se não houver o reconhecimento deste caráter, de nada adiantarão textos escritos assegurando o tratamento de direito humano à água. Viegas (2012) afirma ser indiscutível que o acesso do homem à água é um direito humano fundamental:

A essa conclusão poderiam chegar letrados e iletrados, juristas e não juristas, pois se há algo de que todos dependem é de água. $\mathrm{O}$ direito subjetivo à água não é apenas o bastante para sobreviver. O Direito vai além quando resguarda o mínimo

8 A nivel interno, numerosas constituciones contienen referencias explícitas al derecho al agua, entre ellas las del Ecuador, el Estado Plurinacional de Bolivia, la República Democrática del Congo, Sudáfrica, Uganda y el Uruguay. El derecho a servicios de saneamiento también se consagra en algunas constituciones y legislaciones nacionales, como las de Argelia, el Estado Plurinacional de Bolivia, las Maldivas, Sri Lanka, Sudáfrica y el Uruguay. Otras constituciones aluden a la responsabilidad general del Estado de asegurar el acceso al agua potable y el saneamiento (las constituciones de Camboya, Colombia, Eritrea, Etiopía, Filipinas, Gambia, el Irán (República Islámica del), México, Nigeria, Panamá, Portugal y Zambia) (BRAVO, 2014, p. 12).

9 O empresário austríaco Peter Brabeck-Letmathe, principal financiador de campanha dos partidos de extrema direita naquele país, preside o grupo Nestle desde 2005 e nunca escondeu seu objetivo de tornar o fornecimento da água passível de exploração ainda mais acentuada pelas companhias do setor alimentício. $\mathrm{O}$ comércio de água representa $8 \%$ do capital do conglomerado que, em 2015, totalizaram aproximadamente US\$ 100 bilhões (Correio do Brasil, 2016, texto digital). 
existencial. Esse mínimo deve proporcionar uma vida com dignidade. É por isso que o direito humano fundamental abrange o acesso à água em quantidade e qualidade adequadas para uma vida digna (VIEGAS, 2012, p. 16).

Embora esteja fortemente presente na doutrina mundial, ainda não é pacífica a compreensão da fundamentalidade desse direito, pois o entendimento de que a água merece ser declarada como direito humano ainda não foi alcançado de forma universal. Ainda que seja crescente o número de conferências, discussóes internacionais e instrumentos legais sobre a água, não existe na atualidade um texto que tenha sido reconhecido por todos os Estados do planeta, o qual expressamente declare a água como direito humano. Outro desafio é a carência de instrumentos adequados de fiscalização e coação a fim de que haja a observância das normas já existentes, além da resistência do reconhecimento deste direito pelos Estados, que sustentam que se colocará em risco conceitos como o da soberania nacional, pois são muitos países que resistem e se opóem ao reconhecimento do direito de acesso à água como direito humano, pelo fato de esta colocar em risco conceitos como o da soberania permanente, "sem contar aqueles que resistem a tal possibilidade, sustentando que a água deve ser tratada como mercadoria ${ }^{10}$ (cada vez que há a interrupção do fornecimento de água - seja qual for a causa - parte de uma "desinteressada” mídia sugere a privatização como solução)" (TURATTI, 2014, p. 209).

\section{CONSIDERAÇÓES FINAIS}

Não há ser vivo que consiga sobreviver sem água, afirmação que por si só parece óbvia, mas traz em si a interpretação jurídica da necessidade de se ter o efetivo acesso à água. E isso pressupóe acesso à água de qualidade e em quantidade mínima para que se atendam às necessidades básicas do ser humano. Não há vida sem água, e, sendo a vida um direito humano fundamental incontestavelmente reconhecido, para que haja vida, é necessário acesso à água, retomando a previsão contida na Conferência do Rio de Janeiro, que afirma ser a água um recurso indispensável para a sobrevivência de todas as espécies.

A premissa de que a água pode ser compreendida como um direito fundamental é resultado de uma leitura sistêmica da $\mathrm{CF} / 1988$, especialmente quando esta garante o direito à vida com dignidade e um meio ambiente equilibrado, associado a uma análise conjunta da doutrina especializada que sustenta esta questão.

Como analisado neste artigo, o entendimento de que a água é um direito humano no plano internacional ganhou força graças a três documentos: a Observação Geral no 15 (2002) do Comitê de Direitos Econômicos, Sociais e Culturais; a Resolução no 64/292

10 No Brasil, as notícias sobre a intenção de privatizar o Aquífero Guarani apontam que as negociaçóes com os principais conglomerados transnacionais do setor, entre elas a Nestlé e a Coca-Cola, seguem "a passos largos”. Em entrevista anônima, um alto funcionário da ANA (Agência Nacional das Águas) afirmou: "Representantes destas companhias têm realizado encontros reservados com autoridades do atual governo, no sentido de formular procedimentos necessários à exploraçáo pelas empresas privadas de mananciais, principalmente no Aquífero Guarani, em contratos de concessão para mais de 100 anos" (Correio do Brasil, 2016, texto digital). 
(2010) da Assembleia Geral das Naçóes Unidas e a Resolução no 15/9 (2010) aprovada pelo Conselho de Direitos Humanos das Naçóes Unidas. O primeiro destaca-se por frisar que a água é pressuposto para o exercício e o cumprimento dos demais direitos, sendo essencial para uma vida digna, assim como o fazem a Declaração dos Direitos da Água (ONU, 1992) e o $4^{\circ}$ Fórum Mundial da Água (CONSELHO MUNDIAL DA ÁGUA, texto digital, 2006). O segundo e terceiro documento sáo relevantes porque trazem o reconhecimento pela ONU de que o acesso à água potável é um direito humano e que se deve garantir a efetividade desse direito.

Portanto, para que se construa o entendimento de que a água é um direito humano fundamental, é necessário perceber a fundamentalidade deste direito para a existência da vida, seu caráter transfronteiriço e universal, e a clara conexáo entre estes pressupostos, pois o acesso à água em quantidade e qualidade é pressuposto para uma vida digna. As conferências internacionais, seus documentos e Resoluções confirmam a inegável relação entre água, meio ambiente, saúde e vida digna, o que ajudou a fortalecer a conexão entre o acesso à água e os Direitos Humanos e contribui, consequentemente, para o reconhecimento da água como direito humano fundamental.

Apesar da inexistência de um documento formado por todos os países no sentido de reconhecer a água como direito humano, o tratamento dispendido a este bem nos documentos investigados demonstra haver o reconhecimento tácito desta condição. Mas é necessário que este reconhecimento seja expresso de forma literal também nas Constituiçôes, para que não ocorram dúvidas de interpretação que conduzam à possível mercantilização deste bem, a qual é fortemente influenciada pelos interesses de determinados grupos econômicos. O direito humano à água precisa ocupar seu espaço, mesmo que isto imponha uma ressignificação acerca da soberania dos Estados, pois o que está em jogo é o acesso à água e a manutenção da vida, aspectos que se colocam como superiores a discussão da soberania.

Além disso, políticas públicas perenes, que reconheçam e implementem as legislaçóes protetivas já existentes, garantam a qualidade da água ofertada e uma fiscalização eficiente das normas existentes, necessitam ser implementadas de modo sistemático, sem depender de vontades pessoais ou preferências governamentais, a fim de garantir a dignidade individual e a justiça social.

Assim, para que se possa garantir este direto humano fundamental, não é suficiente apenas que haja uma legislação que garanta isto em nível constitucional e que sejam implementadas políticas públicas referentes a ela, mas também se torna necessário uma mudança de racionalidade, onde os Estados não permitam que interesses econômicos se sobreponham a interesses sociais, solicitando que o cidadáo se engaje na causa da água e possa compreender e percebê-la como um direito humano fundamental e essencial a sua qualidade de vida, propondo açóes, fiscalizando, participando dos processos decisórios, e, essencialmente, agindo de modo sustentável para que este direito seja efetivo. 


\section{REFERÊNCIAS}

BERRETA, M. R. S. Gestáo democrática das águas: os desafios à participação dos agricultores da bacia hidrográfica do Arroio Ribeiro, RS. Tese (Doutorado) Universidade Federal do Rio Grande do Sul, Instituto de Geociências, Programa de Pós-Graduação em Geografia. Porto Alegre, 2013. Disponível em <http://www.lume.ufrgs.br/ handle/10183/77989>. Acesso em 08 jul. 2016.

BOBBIO, N. A era dos direitos. Rio de Janeiro: Campus, 1992.

BRASIL. Constituição (1988). Constituiçáo da República Federativa do Brasil. Disponível em: <http://www.planalto.gov.br/ccivil_03/constituicao/constitui\%C3\%A7ao. htm>. Acesso em 03 nov. 2015.

BRASIL. Lei 9.433, de 8 de janeiro de 1997. Disponível em: <http://www.planalto.gov. br/ccivil_03/leis/19433.htm>. Acesso em 04 out. 2015.

BRASIL. Ministério do Meio Ambiente. Conferência das Naçóes Unidas Sobre Desenvolvimento Sustentável. 2012. Disponível em: <www.mma.gov.br/port/conama/ processos/61AA3835/O-Futuro-que-queremos1.pdf>. Acesso em 23 set. 2016.

BRASIL. Ministério do Meio Ambiente. Declaraçáo de Joanesburgo sobre desenvolvimento sustentável. 2003. Disponível em: <www.mma.gov.br/estruturas/ ai/_arquivos/decpol.doc>. Acesso em: 23 set. 2016.

BRASIL. Ministério do Meio Ambiente (MMA). Brasília, 1992. Agenda 21 Global. Disponível em: <http://www.mma.gov.br/responsabilidade-socioambiental/agenda-21/ agenda-21-global>. Acesso em 13 jul. 2015.

BRAVO, Á. A. S. Injusticia ambiental y derecho humano al agua. Revista Thesis Juris São Paulo, V.3, N.2, pp. 551-566, Julho/Dezembro.2014. Disponível em: <http://www. revistartj.org.br/ojs/index.php/rtj/article/view/186>. Acesso em 10 ago. 2016.

CARVALHO, Carlos Gomes. Introduçáo ao Direito Ambiental. São Paulo: Letras \& Letras, 2001.

CAUBET, C. G. A Água, a Lei e a Política...E o meio ambiente? Curitiba, Editora Juruá, 2008.

CONSELHO MUNDIAL DA ÁGUA. O direito à água $\bigotimes$ do conceito à implementação. 2006. Disponível em: <http://www.worldwatercouncil.org/fileadmin/world_water_ council/documents_old/Library/Publications_and_reports/Right_to_Water_Spanish_ Final.pdf>. Acesso em 01 set. 2014.

D’ISEP, C. F. M. Água juridicamente sustentável. São Paulo: Editora Revista dos Tribunais, 2010. 
FIORILlO, C. A. P. Águas no novo Código Civil: Lei 10.406/02. In: BENJAMIN, A. H.(Org.). Congresso Internacional de Direito Ambiental. Direito, água e vida. São Paulo: Imprensa Oficial, 2003. V. 1.

FIORILlO, C. A. P. Curso de Direito Ambiental Brasileiro. São Paulo: Saraiva, 2013.

LEFF, H. Discursos sustentáveis. Tradução Silvana Cobucci Leite. São Paulo: Cortez, 2010.

MACHADO, P. A. L. Direito Ambiental Brasileiro. 19a ed. rev. atual. e ampl. São Paulo: Malheiros, 2011.

MEDEIROS, F. L. F. Meio Ambiente: direito e dever fundamental. Porto Alegre: Livraria do Advogado, 2004.

MENDES, G.; COELHO, I. M.; BRANCO, P. G. G. Curso de direito constitucional. 5. ed. rev. e atual. São Paulo: Saraiva, 2010.

MIRANDOLA, C. M. S.; SAMPAIO, L. S. Universalização do direito à água. In: BARRAL, W.; PIMENTEL, L. O. (orgs.). Direito Ambiental e desenvolvimento. Florianópolis: Fundação Boiteux, 2006.

MULTINACIONAIS querem privatizar uso da água e Temer negocia. Correio do Brasil. 22 ago. 2016. Disponível em: <http://www.correiodobrasil.com.br/multinacionaisquerem-privatizar-uso-da-agua-e-temer-negocia/>. Acesso em 24 set. 2016.

ORGANIZAÇÃO DAS NAÇÕES UNIDAS (ONU). Comentário Geral no 15 do Comitê de Direitos Econômicos, Sociais e Culturais. 2002. Disponível em: <http://www.un.org/ga/search/view_doc.asp?symbol=A/RES/64/292\&referer=/ english/\&Lang=S>. Acesso em 24 nov. 2015.

ORGANIZAÇÃO DAS NAÇÓES UNIDAS (ONU). Resolução no 15, de 30 de setembro de 2010. Disponível em: <http://www.un.org/ga/search/view_doc. asp?symbol=A/HRC/RES/15/9\&referer=/english/\&Lang=S>. Acesso em 30 nov. 2015.

ORGANIZAÇÃO DAS NAÇÓES UNIDAS (ONU). Resolução no 64/292, de 28 de julho de 2010. Disponível em: <http://www.un.org/ga/search/view_doc.asp?symbol=A/ RES/64/292\&referer=/english/\&Lang=S>. Acesso em 28 nov. 2015.

RAMOS, A. G. B. O panorama hídrico do Brasil e a ambiguidade de soluções: Direitos humanos, participação popular e a experiência da América Latina. Revista Eletrônica Direito e Política, Programa de Pós-Graduação Stricto Sensu em Ciência Jurídica da UNIVALI, Itajaí, v.10, n.2, 2015.

SARLET, I. W.; FENSTERSEIFER, T. Breves consideraçóes sobre os deveres de proteção do Estado e a garantia da proibição de retrocesso em matéria ambiental. In: 
FIGUEIREDO, G. J. P. et al. Código florestal: 45 anos: estudos e reflexões. Curitiba: Letra da Lei, 2010.

SHIVA, V. Las mujeres de Kerala contra Coca-Cola, em Le Monde Diplomatique. Ed. Española, ano IX, n. 113, marzo, 2005, p. 22-23. In: GARCÍA, Anizia. El derecho humano al agua. Editora Trotta, Madrid, 2008.

SILVA, J. A. Direito Ambiental Constitucional. 9. ed. atual. São Paulo: Malheiros, 2011.

TURATTI, L. Direito à água: uma ressignificação substancialmente democrática e solidária de sua governança. Tese. Doutorado em Direito. Programa de Pós-Graduação em Direito - Mestrado e Doutorado em Direito, Universidade de Santa Cruz do Sul UNISC, 2014.

VIEGAS, E C. Gestáo da água e princípios ambientais. 2. ed. Caxias do Sul: Educs, 2012.

VILLAR, P. C. Conflitos pela água e o Direito Humano à água e ao saneamento. In: W. C. R. (Org.). Conflitos e cooperaçáo pela água na América Latina. 1.ed., vol 1. São Paulo: Annablume, 2013.

WOLKMER, M. F. S; MELO, M. P. O Direito Fundamental à água: convergências no plano internacional constitucional. In: MORAES, G. O.; MARQUES JÚNIOR; W. P; MELO, A. J. M. As águas da UNASUL na Rio+20. Curitiba: CRV, 2013. 